\title{
The Investigation of Phase Evolution in Composite Ceramic Superconductors Using Raman Microscopy Techniques
}

\author{
V. A. Maroni and A. K. Fischer \\ Chemical Technology Division \\ Argonne National Laboratory \\ Argonne, IL \\ K. T. Wu \\ State University of New York/Old Westbury Campus \\ Old Westbury, NY 11568
}

December 1999

Prepared for presentation at the $6^{\text {th }}$ International Conference on Materials and Mechanisms of Superconductivity and High Temperature

Superconductors, February 20-25, 2000, Houston, Texas, USA

The submitted manuscript has been created by the University
of Chicago as Operator of Argonne National Laboratory
("Argonne") under Contract No. W-31-109-ENG-38 with the
U.S. Department of Energy. The U.S. Government retains for
itself, and others acting on its behalf, a paid-up, nonexclusive,
irrevocable worldwide license in said article to reproduce,
prepare derivative works, distribute copies to the public, and
perform publicly and display publicly, by or on behalf of the
Government.

*Work sponsored by the U.S. Department of Energy, Energy Efficiency and Renewable Energy, as part of a DOE program to develop electric power technology, under Contract W-31-109-ENG-38. 


\section{DISCLAIMER}

This report was prepared as an account of work sponsored by an agency of the United States Government. Neither the United States Government nor any agency thereof, nor any of their employees, make any warranty, express or implied, or assumes any legal liability or responsibility for the accuracy, completeness, or usefulness of any information, apparatus, product, or process disclosed, or represents that its use would not infringe privately owned rights. Reference herein to any specific commercial product, process, or service by trade name, trademark, manufacturer, or otherwise does not necessarily constitute or imply its endorsement, recommendation, or favoring by the United States Government or any agency thereof. The views and opinions of authors expressed herein do not necessarily state or reflect those of the United States Government or any agency thereof. 


\section{DISCLAIMER}

Portions of this document may be illegible in electronic image products. Images are produced from the best available original document. 


\title{
The Investigation of Phase Evolution in Composite Ceramic Superconductors Using Raman Microscopy Techniques
}

\author{
V. A. Maroni ${ }^{a}$, A.K. Fischer ${ }^{a}$, and K.T. Wu ${ }^{b}$ \\ ${ }^{2}$ Chemical Technology Division, Argonne National Laboratory \\ 9700 South Cass Avenue, Argonne, IL 60439, USA \\ btate University of New York, Old Westbury Campus, Old Westbury, NY 11568, USA
}

Raman microspectroscopy and imaging techniques have been used to investigate key mechanistic features that influence the formation of layered $\mathrm{Bi}$ - and $\mathrm{Tl}$-based superconducting phases during the thermal treatment employed to produce BSCCO and TBCCO composite conductors. Seminal information gained from these studies includes the location of lead-rich nonsuperconducting second phases (NSPs) and the identification of the constituent phases in certain NSP agglomerations that tend to resist dissipation as high-Tc phase formation proceeds to completion.

\section{INTRODUCTION}

Raman microspectroscopy and imaging Raman microscopy offer unique opportunities for studying the evolution and spatial distribution of chemical phases in high-critical-temperature (high-Tc) superconducting ceramics. When applied to compressed /sintered powders, silver-clad composite tapes/wires, and thin films in conjunction with powder $\mathrm{x}$-ray diffraction, scanning electron microscopy, and energy dispersive $\mathrm{x}$-ray spectroscopy, it is possible to gain seminal insights about the identity, size, shape, orientation, and spatial distribution of the various NSPs that form and dissipate during heat treatment of the BSCCO and TBCCO silver-clad composite tapes [1-3]. The results have permitted us to make specific chemical identifications of alkaline earth cuprate and lead-rich NSPs and to map their spatial distribution with respect to the layered superconducting phases.

\section{EXPERIMENTAL}

The experimental methods and instrumentation used in this research are reported elsewhere $[1,2]$.

\section{RESULTS AND DISCUSSION}

Figure 1 presents an illustration of the type of measurement that can be made using Raman microspectroscopy and imaging Raman microscopy. The "defocused Raman spectrum" in Fig. 1 was obtained by spreading the excitation laser over the circled area in the "white light image" of the specimen, which in this case is a transverse view of a fully-processed 19filament $\mathrm{Ag} / \mathrm{Bi}-2223$ composite conductor. In the white light image shown in Fig. 1, the silver sheath region has been darkened by image processing to provide contrast with the super-conducting filaments (three filaments are discernable in the image). From previous phase characterization studies [1-3] we know that the Raman features at 626,570 , and 520 $\mathrm{cm}^{-1}$ are due to $\mathrm{Bi}-2223,(\mathrm{Ca}, \mathrm{Sr})_{14} \mathrm{Cu}_{24} \mathrm{O}_{41}$, and $(\mathrm{Ca}, \mathrm{Sr})_{2} \mathrm{CuO}_{3}$, respectively. Using our imaging Raman microscope in the filter mode [1-2], we are able to determine the location within the circled area in the white light image from which the Raman scattering at each of the three frequencies is occurring as shown by the three circled Raman images to the right of the white light image in Fig. 1. Each of the three Raman images has been corrected to remove background (BG) effects [1-2]. In these three images the white regions represent the locations of the phases scattering at the frequency indicated to the right of each image. The image of the $626 \mathrm{~cm}^{-1}$ feature, $\mathrm{I}(626) / \mathrm{BG}$, reveals that the layered $\mathrm{Bi}-2223$ phase is located in bands along the silver sheath. The images for the 570 and $520 \mathrm{~cm}^{-1}$ features show how the $(\mathrm{Ca}, \mathrm{Sr})_{14} \mathrm{Cu}_{24} \mathrm{O}_{41}$ and $(\mathrm{Ca}, \mathrm{Sr})_{2} \mathrm{CuO}_{3} \mathrm{NSPs}$ tend to agglomerate in the center region of the filament. The appearance of over-lapping phase domains is associated with the penetration depth of the excitation laser. These types of measurements provide new 
information about phase evolution and microstructure development during the synthesis/processing of cuprate-based ceramic superconductors.

\section{ACKNOWLEDGEMENT}

This research was sponsored by the U.S. Department of Energy, Energy Efficiency and Renewable Energy, as part of a DOE program to develop electric power technology, under Contract W-31-109-ENG-38.

\section{REFERENCES}

1. K.T. Wu, A.K. Fischer, V.A. Maroni, and M.W. Rupich, J. Mater. Res., 12 (1997) 1195.

2. V.A. Maroni, A.K. Fischer, and K.T. Wu, Spectroscopy, 12 (1997) 38.

3. V.A. Maroni, A.K. Fischer, and K.T. Wu, in Spectroscopy of Superconducting Materials, E. Faulques (ed.), ACS Symposium Series 730, American Chemical Society, Washington, DC, 1999 , p. 156.

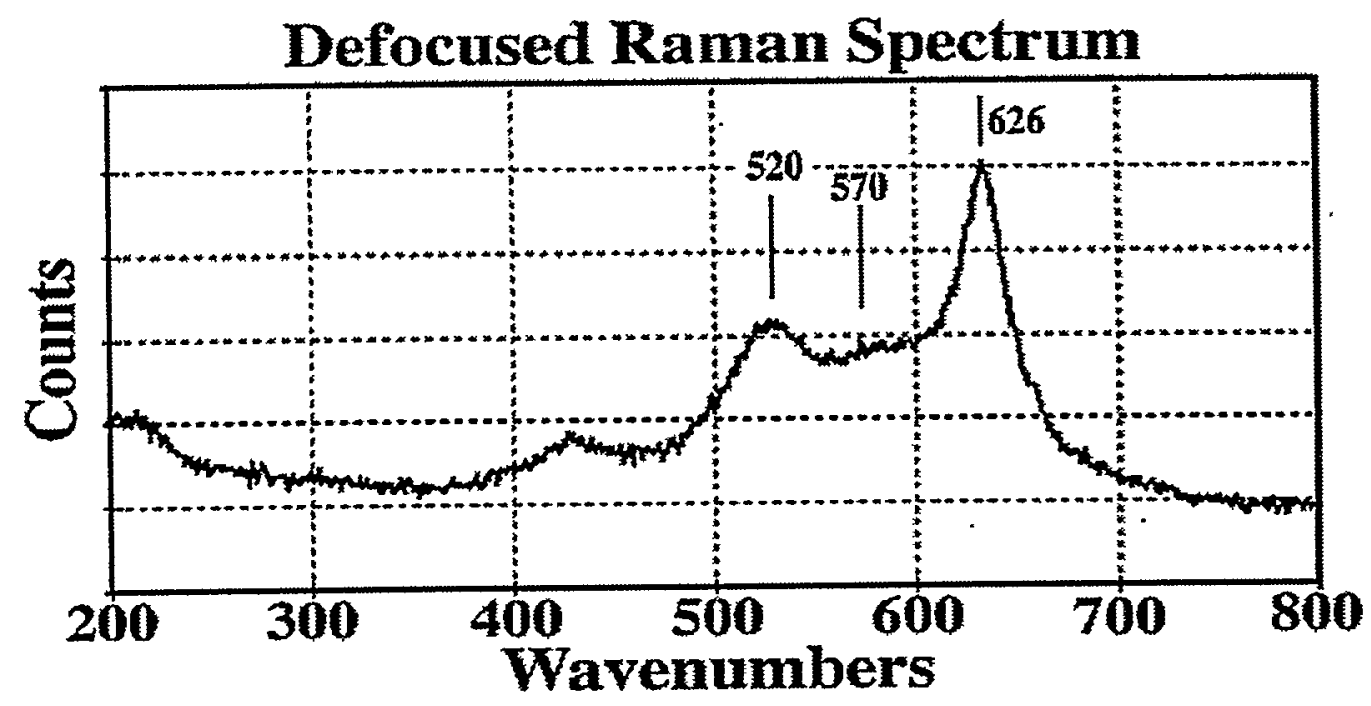

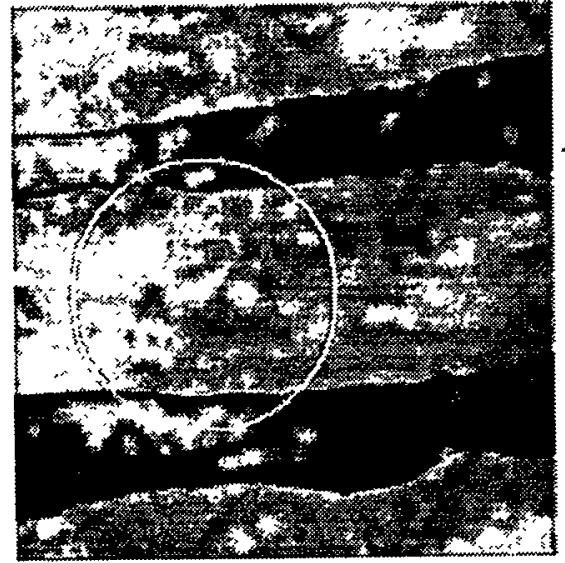

White Light Image

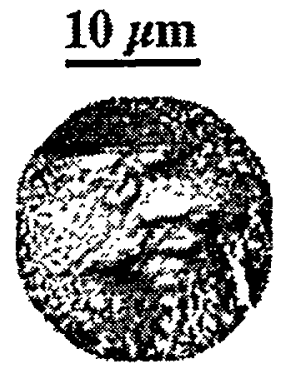

I(520)/BG

$2 / 1$

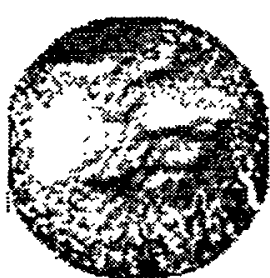

I(570)/BG

$14 / 24$

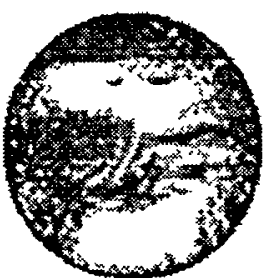

I(626)/BG Matrix

Figure 1. Raman microscopy results for a fully-processed, 19-filament Ag/Bi-2223 composite. (See text for an explanation) 